\title{
COVID-19 pneumonia in kyphoscoliosis: The success stories
}

\author{
Mohd. Mustahsin ${ }^{1}$, Sanjay Choubey ${ }^{1}$, Garima Singh ${ }^{1}$, Madhulika Dubey ${ }^{1}$, Sachin Khanduri², \\ Rachit Sharma $^{3}$, Amit Srivastava ${ }^{3}$ \\ ${ }^{1}$ Department of Anesthesiology and Critical Care, Era's Lucknow Medical College and Hospital, Lucknow; \\ ${ }^{2}$ Department of Radiology, Era's Lucknow Medical College and Hospital, Lucknow; ${ }^{3}$ Department of Pulmonary \\ Medicine, Era's Lucknow Medical College and Hospital, Lucknow
}

\begin{abstract}
Coronavirus disease (COVID-19) pandemic has led to millions of deaths worldwide. Old age, immunocompromised state and multiple comorbidities are described as risk factors. Kyphoscoliosis (KS) is the most common spine abnormality and a risk factor of respiratory failure. Management of pneumonia in a patient with severe kyphoscoliosis is challenging to the intensivist. We report successful management of two patients with severe kyphoscoliosis who developed severe COVID-19 pneumonia.
\end{abstract}

\section{Case \#1}

A 40-year-old male, weighing $68 \mathrm{~kg}$ and body mass index of $26.5 \mathrm{~kg} / \mathrm{m}^{2}$, known case of severe kyphoscoliosis with associated

Correspondence: Dr. Mohd. Mustahsin, EDIC, DM (Critical Care Medicine), Consultant and Head of Critical Care Unit, FFF-2 Doctors Residence, Era's Lucknow Medical College and Hospital, Lucknow 226003, India.

Tel.+91.9871559131. E-mail: mustahsin.malik@gmail.com

Key words: COVID-19; kyphoscoliosis; restrictive lung disease.

Contributions: All the authors have played a significant role in the paper and have read and approved the final version of the manuscript and agreed to be accountable for all aspects of the work.

Conflict of interest: The authors declare that they have no competing interests, and all authors confirm accuracy.

Ethics approval: No ethical committee approval was required for this case report by the Department, because this article does not contain any studies with human participants or animals.

Consent for publication: Written informed consent for use of personal data has been obtained from the patients.

Received for publication: 12 March 2021.

Accepted for publication: 13 June 2021.

${ }^{\circ}$ Copyright: the Author(s), 2021

Licensee PAGEPress, Italy

Monaldi Archives for Chest Disease 2022; 92:1844

doi: 10.4081/monaldi.2021.1844

This article is distributed under the terms of the Creative Commons Attribution Noncommercial License (by-nc 4.0) which permits any noncommercial use, distribution, and reproduction in any medium, provided the original author(s) and source are credited. severe restrictive lung disease and hypertension, presented with chief complaints of fever with chills and rigor for the last 10 days, cough 8 days and shortness of breath 1 day.

On arrival to the hospital triage, his vitals showed a heart rate (HR) of $84 / \mathrm{min}$, blood pressure (BP) $118 / 78 \mathrm{mmHg}$, respiratory rate $(\mathrm{RR}) 32 / \mathrm{min}$, temperature $98.7^{\circ} \mathrm{F}$ and his oxygen saturation was $79 \%$ on room air which increased to $94 \%$ on administration of oxygen at $15 \mathrm{~L} / \mathrm{min}$ by non-rebreathing mask (NRM). He was categorized as severe COVID-19 as per World Health Organization (WHO) criteria [1] and shifted to Intensive Care Unit (ICU). On examination in ICU, he had a RR of 36/min and was using accessory muscles of respiration. His Arterial Blood Gas analysis (ABG) on NRM (15 1/min oxygen) revealed a $\mathrm{pH}$ of 7.12, $\mathrm{pCO}_{2} 115 \mathrm{mmHg}, \mathrm{pO}_{2} 82 \mathrm{mmHg}, \mathrm{HCO}^{3-} 39 \mathrm{mmol} / \mathrm{l}$ and $\mathrm{SaO}_{2}$ $99 \%$ with $\mathrm{PaO}_{2} / \mathrm{FiO}_{2}$ value approximately 100 . The patient was immediately taken on non-invasive ventilation (Maquet ventilator). The 'set parameters' of non-invasive positive pressure ventilation (NIPPV) during initiation of support with non-vented oronasal mask to the patient on pressure support mode had a CPAP of $8 \mathrm{~cm} \mathrm{H} \mathrm{H}_{2} \mathrm{O}$, Pressure support (PS) of $5 \mathrm{~cm} \mathrm{H}_{2} \mathrm{O}$ and $\mathrm{FiO}_{2}$ 1.0. His laboratory findings were suggestive of leukocytosis (total leucocyte count $12.6 \times 10^{9} / 1$ ), polymorphs $76 \%$, lymphocytes $19 \%$, glucose $310 \mathrm{mg} / \mathrm{dl}$, urea $40 \mathrm{mg} / \mathrm{dl}$, creatinine $1.4 \mathrm{mg} / \mathrm{dl}$, calcium 9.8 $\mathrm{mg} / \mathrm{dl}$, albumin $2.5 \mathrm{~g} / \mathrm{dl}$, lactate $2.3 \mathrm{mmol} / \mathrm{l}$, procalcitonin 0.226 ng/ml, IL-6 28 pg/ml, CRP 33 mg/L, ferritin >1000 ng/ml and ddimer $7.18 \mathrm{mcg} / \mathrm{ml}$.

His initial chest X-ray showed severe scoliosis with convexity towards right and diffuse air space opacification more on right lung (Figure 1). His CT scan showed multifocal peripherally based ground glass opacities with consolidation in right middle and lower zones. His EKG showed normal sinus rhythm. His nasopharyngeal swab for COVID-19 RT-PCR came positive. He was started on treatment with remdesivir, dexamethasone, meropenem, doxycycline and low molecular weight heparin (subcutaneous twice daily).

Serial ABGs at regular intervals guided us to change the set ventilatory parameters as per the need of the patient for optimum ventilation. Due to his worsening respiratory distress, he was intubated and placed on closed circuit mechanical ventilation [volume control mode (VCV) with $\mathrm{FiO}_{2}$ 1.0, tidal volume $290 \mathrm{ml}$, PEEP $14 \mathrm{~cm} \mathrm{H}_{2} \mathrm{O}$, peak airway pressure $35 \mathrm{~cm} \mathrm{H}_{2} \mathrm{O}$, plateau pressure $29 \mathrm{~cm} \mathrm{H}_{2} \mathrm{O}$ and RR 24/min]. He was nursed in lateral positions with 3 hourly position change. Gradually his oxygen requirement decreased and his ventilatory parameters improved with $\mathrm{pCO}_{2}$ decreasing to 47 $\mathrm{mmHg}$. On $3^{\text {rd }}$ day of admission, he was weaned off and extubated. He was then placed on NIPPV support. On $5^{\text {th }}$ day he was removed from NIPPV during day time and started on oral diet the same day. Over next 7 days he required NIPPV only during sleep. Thereafter he was weaned off nocturnal non-invasive ventilation, mobilized 
out of bed and shifted to ward. He was finally discharged from the hospital on $14^{\text {th }}$ day of hospital admission.

\section{Case \#2}

A 62-year-old male, weighing $43 \mathrm{~kg}$ and body mass index of $19.1 \mathrm{~kg} / \mathrm{m}^{2}$, known case of severe kyphoscoliosis with severe restrictive lung disease. Presented with complaints of fever for the last 3 days, breathlessness 3 days and generalized weakness 3 days. This patient was referred to our institute from a peripheral hospital as his nasopharyngeal swab for RT-PCR had tested positive.

On arrival to hospital triage his vitals were: HR 104/min, BP $140 / 70 \mathrm{mmHg}$, RR 34/min, temperature $36.5^{\circ} \mathrm{C}$ and oxygen saturation $87 \%$ on $81 / \mathrm{min}$ oxygen via facemask. He had been using his accessory muscles of respiration. He was started on NIPPV with non-vented oro-nasal mask on pressure support mode with $\mathrm{FiO}_{2}$ 1.0, CPAP $10 \mathrm{~cm} \mathrm{H}_{2} \mathrm{O}$ and PS $5 \mathrm{~cm} \mathrm{H}_{2} \mathrm{O}$ immediately in the triage. His $\mathrm{ABG}$ showed $\mathrm{pH}$ of 7.35, $\mathrm{pCO}_{2} 61 \mathrm{mmHg}, \mathrm{pO}_{2} 75 \mathrm{mmHg}$, $\mathrm{HCO}^{3-} 33.7 \mathrm{mmol} / \mathrm{L}$ and $\mathrm{SO}_{2} 94.1 \%$ with $\mathrm{PaO}_{2} / \mathrm{FiO}_{2}$ calculated out to be 75. He was categorized as severe COVID-19 [1] and was shifted to ICU. His labs showed TLC- $9.6 \times 10^{9} / \mathrm{L}$, DLC (N-89\%, L- $6 \%$, M-2\%, E-3\%), creatinine $0.4 \mathrm{mg} / \mathrm{dl}$, urea $21 \mathrm{mg} / \mathrm{dl}$, glucose $170 \mathrm{mg} / \mathrm{dl}$, calcium $8.2 \mathrm{mg} / \mathrm{dl}$, albumin $3.2 \mathrm{~g} / \mathrm{dl}$, lactate 1.4 $\mathrm{mmol} / \mathrm{L}$, procalcitonin $0.226 \mathrm{ng} / \mathrm{ml}$, IL-6 $13.96 \mathrm{pg} / \mathrm{ml}$, CRP 42 $\mathrm{mg} / \mathrm{L}$, ferritin $65.5 \mathrm{ng} / \mathrm{mL}$ and D-Dimer $0.72 \mathrm{mcg} / \mathrm{ml}$.

His chest X-ray showed airspace opacification in bilateral lung fields with blunting of costo-phrenic angles. Scoliosis was noted with curvature towards right side. His NCCT thorax showed bilateral pleural effusion (left>right) with patchy areas of ground glass opacities in bilateral lung parenchyma and kyphoscoliosis with curvature towards right side (Figure 2 A,B). His EKG showed normal sinus rhythm with low voltage complexes and there was no axis deviation. His treatment started with remdesivir, doxycycline, ivermectin, dexamethasone and low molecular weight heparin (subcutaneous twice daily). NIPPV was continued with oxygen via intermittent high flow nasal cannula (HFNC) during feeding.

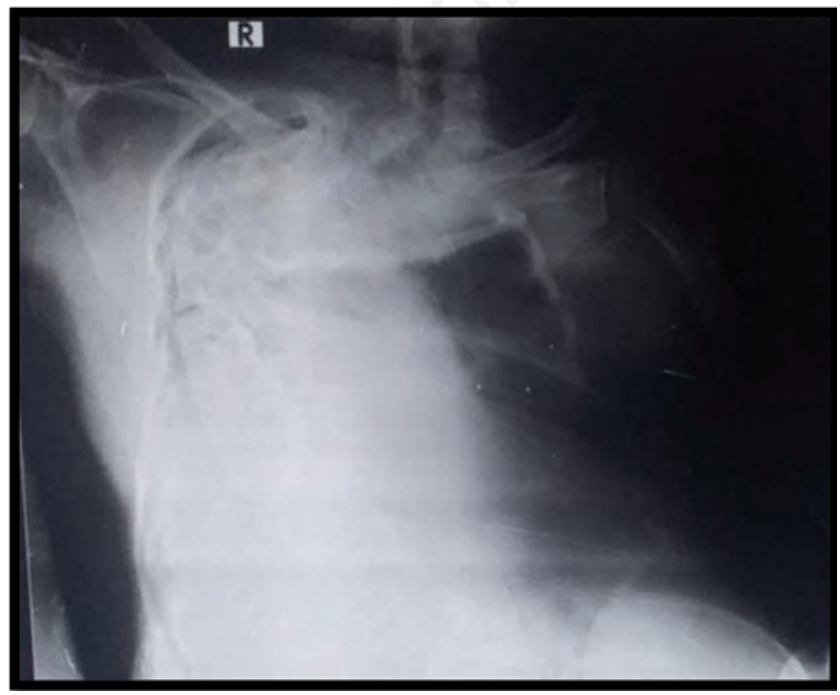

Figure 1. Chest X-ray showing severe scoliosis with bilateral opacities more on right side.
On $5^{\text {th }}$ day of ICU admission, his oxygenation $\left(\mathrm{PaO}_{2} / \mathrm{FiO}_{2} 220\right)$ and ventilatory parameters improved and he was taken off NIPPV during daytime. Mobilization was started and NIPPV was required only during sleep for the next 5 nights. He was subsequently shifted out of the ICU and ultimately discharged from the hospital on day 12 of hospital admission.

\section{Discussion}

Kyphoscoliosis is a common skeletal deformity with excessive forward and lateral curvature of the spine. It increases the work of breathing due to reduced chest wall compliance and decreases the effectiveness of the respiratory muscles leading to hypoventilation, hypercapnia and progressive chronic respiratory failure. Respiratory tract infections in these patients can precipitate acute respiratory failure which may require ICU admission for non-invasive or invasive mechanical ventilation $[2,3]$.

The literature of COVID-19 pneumonia in kyphoscoliotic patient is scarce at present. Sahu et al. [4] published the index case of a 57-year-old male, a known case of kyphoscoliosis with severe restrictive lung disease, who developed COVID-19 pneumonia and died on $5^{\text {th }}$ day of stay in the hospital.

We have encountered two patients of severe kyphoscoliosis with severe restrictive lung disease, who developed COVID-19 pneumonia. Both patients were successfully managed in the ICU. The first patient (Case \#1) required invasive ventilation due to NIPPV failure and the latter was successfully managed with NIPPV (Case \#2). Both patients had raised baseline $\mathrm{pCO}_{2}$ suggesting that COVID-19 pneumonia may be a precipitating factor for the underlying respiratory failure and not the primary abnormality.

In chest wall diseases, non-invasive ventilation is the recommended treatment option [5]. Although the initial literature on use of NIPPV in COVID-19 patients suggested that NIPPV may generate aerosol which might transmit infection to the healthcare personnel. However, human laboratory data has suggested that risk of aerosol generation is far less than the benefits of NIPPV [6-8]. We preferred non-invasive ventilation pressure support mode (NIVPS) over pressure control as our patient was conscious and more compliant on the set ventilatory parameters with a belief that the deranged blood gases would start normalizing with passage of time. We intubated Case \#1 only after the failure of NIPPV trial in view of deterioration of his respiratory parameters as per our clinical assessment and as indicated in serial ABGs. Many studies have suggested the successful use of NIPPV in COVID-19 patients. Cheung et al. in a case series of 20 patients with severe COVID pneumonia reported that NIPPV prevented intubation in $70 \%$ of the patients [9]. However few studies have also suggested that early intubation and lung protective ventilation is better in COVID-19 pneumonia thus preventing patient self-induced lung injury (P-SILI) associated with NIPPV $[10,11]$. We aimed to maintain the tidal volume below $6 \mathrm{ml} / \mathrm{kg}$ of predicted body weight during invasive ventilation to avoid ventilator induced lung injury (VILI). We had extubated our patient after two days of invasive mechanical ventilation and post-extubation the patient required NIPPV over a prolonged period of time. Extubation to NIV is also beneficial in recovery profile and outcome in restrictive lung disease associated with kyphoscoliosis [12]. However, a fairly prolonged course of NIPPV had to be instituted before our patients could be shifted to oxygen support by facemask. This strategy was backed by findings of Buyse et al. [13]. Patient with KS is known to hypoventilate during sleep that can lead to hypoxemia and 


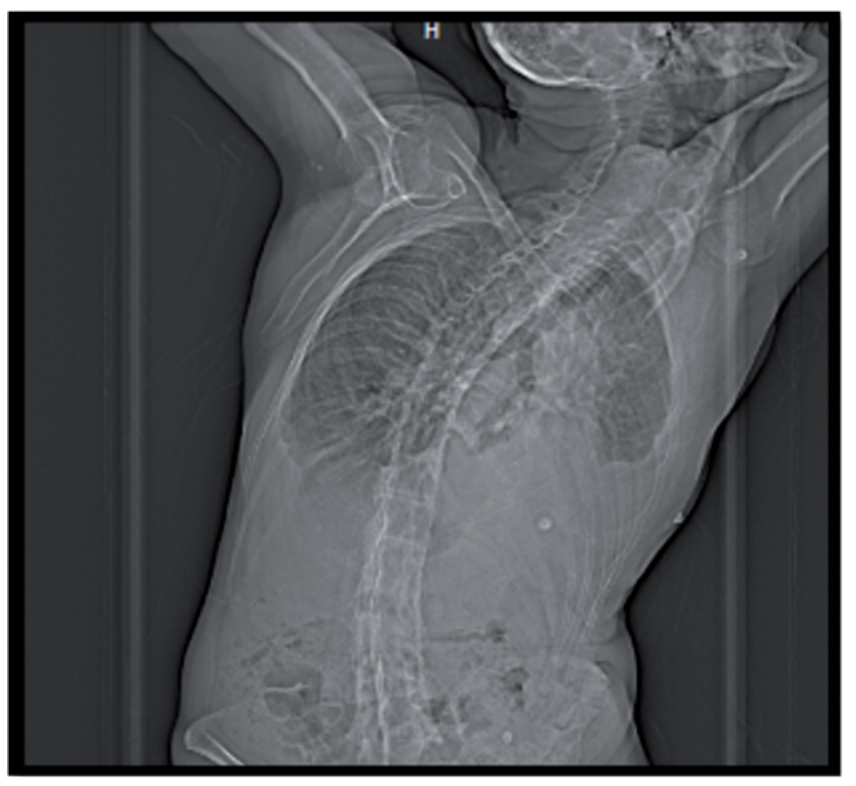

A
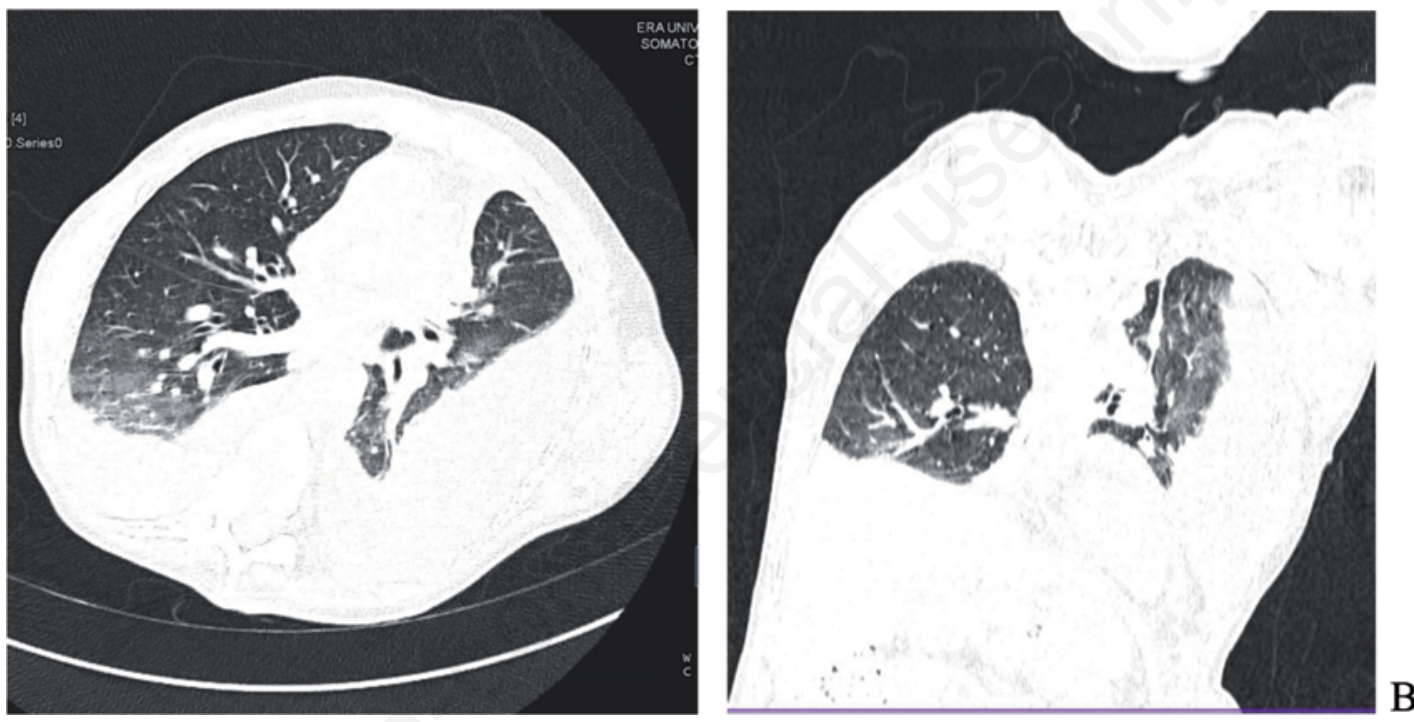

Figure 2. A) NCCT thorax showing bilateral pleural effusion (left>right) with airspace opacification noted in bilateral lung field. Kyphoscoliosis is noted with curvature towards right side. B) CT thorax shows bilateral pleural effusion with patchy areas of ground glass opacities noted in bilateral lung parenchyma.

hypercapnia which may require NIPPV while sleeping. Studies have shown that NIPPV assistance in kyphoscoliotic patients during sleep improves nocturnal desaturation and hypercapnia due to hypoventilation $[14,15]$.

Many studies have pointed out that the chronic lung disease is a risk factor for mortality in patients with COVID-19. Interestingly, like other chronic lung diseases (asthma, COPD and Interstitial lung disease), the restrictive lung disease as a result of kyphoscoliosis has not found a mention in the list of risk factors for COVID-19 pneumonia [16,17].

\section{Conclusions}

To our knowledge, these are the first successfully managed cases of severe kyphoscoliotic patients who developed severe
COVID-19 pneumonia. The successful management of these patients emphasizes that early and aggressive intensive care management of these patients could lead to a favorable outcome. In view of the continuing pandemic, more and more cases of restrictive lung diseases following skeletal deformities may require critical care admissions. Our experience with above two cases suggests that a trial of NIPPV in such patients would enhance the clinical outcome, thereby avoiding the complications of invasive ventilation. This however does not obviate the need for timely invasive ventilation in case of NIPPV trial failure. 
tions/i/item/WHO-2019-nCoV-clinical-2021-1

2. Bergofsky EH. Respiratory failure in disorders of the thoracic cage. Am Rev Respir Dis 1979;119:643-69.

3. Banfi P, Redolfi S, Robert D. Home treatment of infectionrelated acute respiratory failure in kyphoscoliotic patients on long-term mechanical ventilation. Respir Care 2007;52:713-9.

4. Sahu KK, Mishra AK, Martin K, et al. COVID-19 and restrictive lung disease: A deadly combo to trip off the fine balance. Monaldi Arch Chest Dis 2020;90:1346.

5. No authors listed. Clinical indications for noninvasive positive pressure ventilation in chronic respiratory failure due to restrictive lung disease, COPD, and nocturnal hypoventilation-a consensus conference report. Chest 1999;116:521-34.

6. Tran K, Cimon K, Severn M, et al Aerosol generating procedures and risk of transmission of acute respiratory infections to healthcare workers: a systematic review. PLoS One 2012;7: e35797.

7. Simonds AK, Hanak A, Chatwin M, et al Evaluation of droplet dispersion during non-invasive ventilation, oxygen therapy, nebuliser treatment and chest physiotherapy in clinical practice: implications for management of pandemic influenza and other airborne infections. Health Technol Assess 2010;14:131-72.

8. Phua J, Weng L, Ling L, et al. Intensive care management of coronavirus disease 2019 (COVID-19): challenges and recommendations. Lancet Respir Med 2020;8:506-17.

9. Cheung TM, Yam LY, So LK, et al Effectiveness of noninvasive positive pressure ventilation in the treatment of acute respiratory failure in severe acute respiratory syndrome. Chest
2004; 126:845-50.

10. Marini JJ, Gattinoni L. Management of COVID-19 respiratory distress. JAMA 2020;323:2329-30.

11. Brochard L, Slutsky A, Pesenti A. mechanical ventilation to minimize progression of lung injury in acute respiratory failure. Am J Respir Crit Care Med 2017;195:438-42.

12. Ou J, Chen H, Li L, Zhao L, Nie N. The role of non-invasive ventilation used immediately after planned extubation for adults with chronic respiratory disorders. Saudi Med J 2018;39:131-6.

13. Buyse B, Meersseman W, Demedts M. Treatment of chronic respiratory failure in kyphoscoliosis: oxygen or ventilation? Eur Respir J 2003;22:525-8.

14. Laserna E, Barrot E, Beiztegui A. Non-invasive ventilation in kyphoscoliosis. A comparison of a volumetric ventilator and a BIPAP support pressure device. Arch Bronconeumol 2003;39:13-8.

15. Elliott MW Non-invasive ventilation during sleep: time to define new tools in the systematic evaluation of the technique. Thorax 2011;66:82-4.

16. Chen N, Zhou M, Dong X, et al. Epidemiological and clinical characteristics of 99 cases of 2019 novel coronavirus pneumonia in Wuhan, China: a descriptive study. Lancet 2020;395:507-13.

17. Chang D, Lin M, Wei L, et al. Epidemiologic and clinical characteristics of novel coronavirus infections involving 13 patients outside Wuhan, China. JAMA 2020;323:1092-3. 